\title{
The role of transanal total mesorectal excision in rectal surgery
}

\author{
Shlomo Yellinek, Steven D. Wexner \\ Cleveland Clinic Florida, Department of Colorectal Surgery, Weston, FL 33331, USA.
}

Correspondence to: Dr. Steven D. Wexner, Cleveland Clinic Florida, Department of Colorectal Surgery, 2950 Cleveland Clinic Blvd., Weston, FL 33331, USA. E-mail: wexners@ccf.org

\begin{abstract}
How to cite this article: Yellinek S, Wexner SD. The role of transanal total mesorectal excision in rectal surgery. Mini-invasive Surg 2018;2:22. http://dx.doi.org/10.20517/2574-1225.2018.17
\end{abstract}

Received: 10 Apr 2018 First Decision: 21 Jun 2018 Revised: 18 Jul 2018 Accepted: 20 Jul 2018 Published: 2 Aug 2018

Science Editor: Gordon N. Buchanan Copy Editor: Jun-Yao Li Production Editor: Huan-Liang Wu

\begin{abstract}
Transanal total mesorectal excision (TaTME) is the newest approach for the resection of rectal cancer, according to the principles of TME. The evolution of TaTME started almost 40 years ago and is a combination of several important developments in both micro-endoscopic surgery and transanal surgery. The preliminary clinical data have revealed acceptable TME quality. Clinical trials to determine the long-term oncological results are still in process. In order to master TaTME, the surgeon should be an expert in laparoscopic rectal surgery as well as transanal microsurgery and follow a stepwise training approach. Robotic TaTME using a single-port robotic system is a promising future development.
\end{abstract}

Keywords: Transanal total mesorectal excision, rectal cancer, single port robotic proctectomy, transanal total mesorectal incision training

\section{INTRODUCTION AND HISTORY}

The evolution of transanal total mesorectal excision (TaTME) began with the introduction of TME by Heald et al. ${ }^{[1]}$. In 1982, they showed a reduction in the local recurrence rate from $40 \%$ to $<10 \%$ by employing TME. Components of TME include a complete or near complete rather than an incomplete mesorectal specimen, tumor-free circumferential resection margins (CRM), a tumor-free distal resection margin (DRM), and the assessment of $\geq 12$ lymph nodes. Initially, the operation was done in an open, trans-abdominal approach. In 1991, Marks et al. ${ }^{[2]}$ presented the transabdominal-transanal (TATA) approach to low rectal cancer. Dr. Marks' rationale was that the transanal approach allows the surgeon to achieve distal resection margins under direct visualization and facilitates distal dissection ${ }^{[2]}$. The next step in the evolution

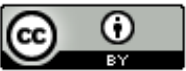

(C) The Author(s) 2018. Open Access This article is licensed under a Creative Commons Attribution 4.0 International License (https://creativecommons.org/licenses/by/4.0/), which permits unrestricted use sharing, adaptation, distribution and reproduction in any medium or format, for any purpose, even commercially, as long as you give appropriate credit to the original author(s) and the source, provide a link to the Creative Commons license, and indicate if changes were made. 
of TaTME was the introduction of transanal endoscopic surgery (TEM). In 1992, Buess et al. ${ }^{[3]}$ presented their experience with TEM, which utilizes a $40-\mathrm{mm}$ operating rectoscope sealed with an airtight face piece. Carbon dioxide is constantly infused, thereby distending the rectum and maintaining visibility. A variety of operating instruments can be inserted through the face piece to resect adenomas and selected early carcinomas of the mid and upper rectum $^{[3]}$. In 2010, Sylla et al. ${ }^{[4]}$ presented the first case of TaTME using TEM and laparoscopy that had been performed in a 76-year-old patient with a T2N2 rectal cancer treated with preoperative chemoradiation. The specimen was transanally transected followed by a hand sewn coloanal anastomosis. TEM was not widely adopted due to its high costs, technical complexity and the long learning curve. However, Maya et al. ${ }^{[5]}$ showed by Cussum analysis that the learning curve for TEM is associated with a significant decrease in operative time after only four cases.

Atallah et al. ${ }^{[6,7]}$ presented the use of transanal single port laparoscopy through the anal canal (transanal minimally invasive surgery; TAMIS). A single-incision laparoscopic surgery port was introduced into the anal canal to gain endoscopic access to the rectum, pneumorectum was established, and transanal excision was performed using laparoscopic instruments.

TaTME combines the TAMIS and trans-abdominal approaches in order to achieve TME. Several potential advantages have been postulated. Atallah was the first to describe this combination of techniques including a detailed video and the results of the 20 first cases ${ }^{[8,9]}$. Rectal distention with $\mathrm{CO}_{2}$ combined with magnified optics permits excellent visualization of tissue planes. Easier access to the low rectum may aid the surgeon with better quality TME and precise selection of the distal resection margin under direct visualization helps ensure an adequate margin. TaTME may potentially be a safer anastomosis by avoiding the multiple stapler firings often required in the abdominal approach and may result in higher rates of sphincter preserving surgery. Finally, the two-team approach can shorten the length of surgery.

\section{CLINICAL TRIALS}

Lacy et al ${ }^{[10]}$ reported a series of 140 patients who underwent TaTME for rectal cancer. The mean operative time was $166 \mathrm{~min}$ and there were no conversions or intraoperative complications. Macroscopic quality assessment of the resected specimen was complete in $97.1 \%$ and near complete in $2.1 \%$. Thirty-day morbidity was minor (Clavien-Dindo I-II) in $24.2 \%$ and major (Clavien-Dindo III-IV) in $10 \%$, and no mortality occurred within the first 30 days. The mean follow-up was 15 months, with a $2.3 \%$ local recurrence rate and a $7.6 \%$ rate of systemic recurrence.

De Lacy et al. ${ }^{[11]}$ subsequently reported the pathological results of 186 patients who underwent TaTME for low $(37 \%)$ or mid (63\%) rectal cancer. Mesorectal resection quality was complete in $95.7 \%$, near complete in $1.6 \%$, and incomplete in $1.1 \%$. Overall positive CRM and DRM were $8.1 \%$ and $3.2 \%$, respectively. The composite of complete mesorectal excision, negative CRM, and negative DRM was achieved in $88.1 \%$ of patients.

Penna et al.$^{[12]}$ reported the short-term clinical and oncological results of the first 720 patients on behalf of the International Registry for TaTME. Seven hundred and twenty consecutive patients from 66 registered units in 23 countries included 634 patients with rectal cancer and 86 with benign pathology. Conversion to open surgery was $6.3 \%$ and the mesorectum was complete in $86 \%$, near complete in $11 \%$, and incomplete in $4 \%$. The R1 resection rate was $2.7 \%$. Post-operative morbidity and mortality were $32.6 \%$ and $0.5 \%$, respectively. Risk factors for poor specimen (incomplete specimen, perforation, R1 resection) on multivariate analysis were positive CRMs on preoperative MRI and very low rectal tumors $(<2 \mathrm{~cm}$ from anal verge).

Using the same TaTME registry, Penna et al. ${ }^{[13]}$ reported the incidence and risk factors for anastomotic failure in 1594 patients who underwent TaTME, 96.6\% of which were performed for cancer and the rest for 
benign pathology. The overall anastomotic failure rate was $15.7 \%$ including early leak (7.8\%), delayed leak (2.0\%), pelvic abscess $(4.7 \%)$, anastomotic fistula (0.8\%), chronic sinus (0.9\%), and anastomotic stricture (3.6\%). Independent risk factors of anastomotic failure were male sex, obesity, smoking, diabetes mellitus, tumors $>25 \mathrm{~mm}$, excessive intraoperative blood loss, manual anastomosis, and prolonged operative time.

Koedam et al. ${ }^{[14]}$ assessed the patient-reported quality of life of 30 consecutive patients who underwent TaTME for rectal cancer. Quality of life was assessed by three questionnaires: Overall Quality of Life (EQ5D-3L), Colorectal Cancer Specific Quality of Life (EORTC: QLQ-C30 and QLQ-CR29) and Anterior Resection Syndrome (LARS) scale. Outcomes of the questionnaires at 1 and 6 months were compared with preoperative (baseline) values. Deterioration for all domains was mainly observed at 1 month after surgery compared to baseline, but most outcomes had returned to baseline at 6 months. Social function and anal pain remained significantly worse at 6 months compared to baseline. Major LARS (score > 30) was 33\% at 6 months after ileostomy closure. End colostomies were not required in any patients. The authors concluded that TaTME is associated with acceptable quality of life and functional outcome at 6 months after surgery comparable to published results after conventional laparoscopic low anterior resection.

Marks et al ${ }^{[15]}$ reported the long-term outcomes of 373 patients with rectal cancer underwent TaTME. Ninety six percent of TME specimens were complete/near complete, $94 \%$ had a negative circumferential resection margin, and $98.6 \%$ had a negative distal margin. Perioperative morbidity and mortality rates were $13.4 \%$ and $0.3 \%$, respectively. The median follow up was 5.5 years. Overall local recurrence, distal metastasis, and 5-year survival was 7.4\%, $19.5 \%$, and $90 \%$, respectively.

In a case matched study that included 300 patients, Perdawood et al.$^{[16]}$ compared TaTME $(n=100)$, laparoscopic TME (LaTME; $n=100$ ), and open TME (OpTME; $n=100)$. The authors reported that TME resulted in lower rates of incomplete TME specimens than LaTME, but not OpTME $(P=0.016, P=0.750$, respectively). The rates of CRM involvement, mean CRM distance, and the percentages of successful surgery were comparable among the three groups $(P=0.368)$. The conversion to open surgery occurred only in the LaTME group. TaTME resulted in shorter operation time and less blood loss than the other two groups $(P$ $<0.001$ and $P<0.001)$. Hospital stay was shorter in the TaTME group $(P=0.002)$; complication rate and mortality were comparable among the groups.

The COLOR III randomized controlled trial is being conducted to evaluate the role of TaTME in rectal cancer and to assess oncological outcomes. It has been designed to compare short- and long-term outcomes of transanal and laparoscopic TME for mid and low rectal cancer. A total of 1098 consecutive patients scheduled for resection of a mid or low rectal carcinoma will be included. The distal border of the tumor has to be within $10 \mathrm{~cm}$ of the anal verge on MRI scan. Exclusion criteria are T1 tumors that can be treated by local excision, tumors with ingrowth in the internal sphincter or levator ani muscle, and all T4 tumors. All participating centers in the COLOR III trial will keep the coordinating center informed of all patients presenting with rectal cancer ${ }^{[17]}$.

The ETAP-GRECCAR 11 randomized controlled trial is also comparing TaTME to laparoscopic TME. Patients with T3 lower-third rectal adenocarcinomas for whom conservative surgery with manual coloanal anastomosis is planned will be recruited. The study is designed as a non-inferiority trial with a main criterion of Ro/R1 resection. The inclusion period will be 3 years, and every patient will be followed for 3 years. The number of patients needed is $226^{[18]}$.

The US Multicenter study of TaTME with laparoscopic assistance for rectal cancer is a single arm feasibility trial sponsored by the Society of American Gastrointestinal and Endoscopic Surgeons and the American Society of Colon and Rectal Surgeons. The primary investigator, Patricia Sylla, aims to enroll 100 patients from 11 sites. 


\section{TRAINING PROGRAM}

Although the early results from the international TaTME registry are encouraging, the participating surgeons encountered intraoperative complications and difficulties in up to $40 \%$ of procedures. These difficulties include unstable pneumorectum, ineffective smoke evacuation, and difficulty developing the correct plane. The specific intraoperative complications associated with TaTME included wrong plane dissection, which may cause presacral bleeding if the dissection plane is too posterior, or injury to the hypogastric nerve bundles if the dissection plane is too lateral. The membranous urethra in males is also vulnerable when dissection is too anterior. Those specific complications and difficulties highlight the need for structured and accredited training program. Several authors have addressed the proper training pathway to the incorporation of TaTME into clinical practice ${ }^{[19-25]}$.

McLemore et al. ${ }^{[24]}$ developed 6 key elements for the safe practice of TaTME. The authors recommended expertise in TME, laparoscopic colorectal surgery, transanal minimally invasive surgery, and intersphincteric dissection. Appropriately qualified individuals should then practice in cadaver models and enter all data in a clinical registry.

Francis et al. ${ }^{[22]}$ conducted a consensus agreement from 207 colorectal surgeons across 18 countries including 52 TaTME specialists. They recommended that prerequisites to learn TaTME should include 3 factors: the trainee, the mentor, and the training facility. The trainee must be an accredited laparoscopic colorectal surgeon with experience of more than 30 laparoscopic TME cases, more than 5 TEM/TAMIS cases, and that the anticipated volume of TaTME cases will be more than 20 per year. The mentor must have performed at least 30 TaTMEs, is experienced in cadaveric training, and has at least two publications per year in the field of TaTME. The training facility should have a cadaveric lab and at least 10 trainees and at least 2 courses per year. For the training curriculum, the authors' recommendation includes 4 stages: self-learning, cadaver workshop, proctorship of the initial 5-10 cases, and, finally, independent practice with continued collection input into the registry.

Koedam et al. ${ }^{[26]}$ evaluated the learning curve of TaTME in 138 patients with rectal cancer over a 60-month period. The authors reported improvement in postoperative outcomes after the first 40 patients, showing a decrease in major postoperative complications from $47.5 \%$ to $17.5 \%$ and leakage rate from $27.5 \%$ to $5 \%$. In addition, the mean operative time ( $42 \mathrm{~min}$ ) and conversion rate (from $10 \%$ to $0 \%$ ) was lower after transitioning to a two-team approach, although neither endpoint decreased with experience.

\section{PRESENT AND FUTURE}

Anatomical factors that may make TaTME a preferred approach for rectal cancer include male gender, low cancers, narrow pelvis, high body mass index, and distorted tissue planes due to neoadjuvant radiotherapy ${ }^{[27-29]}$. Although the use of TaTME seems clearly advantageous for the treatment of mid and low rectal cancer, there are potential advantages to its use in upper rectal cancer, above the peritoneal reflection. Early in the learning curve it is easier to perform TaTME in higher tumors and use those cases in order to gain experience in TaTME for the more challenging, distal cancer cases. The second reason to approach upper rectum cancer transanally is the fact that the rectal specimen is of better quality in TaTME approach ${ }^{[30,31]}$. TaTME may also serve as a useful platform for proctectomy for benign diseases such as inflammatory bowel disease requiring proctectomy, rectal stricture, radiation proctitis, and Hartmann's procedure reversal.

Leo et al.$^{[32]}$ reported their experience of 16 total proctocolectomies and ileal pouch anal anastomoses (TPC + IPAA) for refractory mucosal ulcerative colitis using TaTME-assisted single port laparoscopy. The median operative time was 247 (185-470) min and the overall conversion rate to open surgery was $18.7 \%$. The 30 - 
day surgical complication rate was 37.5\% (Clavien-Dindo 1 in four patients, 2 in one patient and 3 in one patient who developed anastomotic leak). Carvello et al $^{[33]}$ reported a case of TaTME assisted laparoscopic TPC + IPAA for familial adenomatous polyposis (FAP) with satisfactory results. Ambe et al. ${ }^{[34]}$ reported their experience with 8 patients who underwent TaTME assisted laparoscopic TPC + IPAA for FAP. In all cases, surgery was successfully completed using TaTME and no perioperative complications were recorded. Trépanier et al. ${ }^{[35]}$ described their technique and experience with 10 patients who underwent reversal of Hartmann's procedure using combined laparoscopic and TaTME approaches. Indications for Hartmann's procedure were complicated diverticulitis, anastomotic leak, and rectosigmoid cancer. Reconstruction was achieved in all patients. One low colorectal anastomosis was hand sewn and the other 9 were stapled. Diverting loop ileostomies were created in five patients and all were closed during the following year. One case required hand-assistance but there was no conversion to open surgery. Three patients had a total of four post-operative complications, none of whom required reoperation.

Robotic technology includes 3-D optical visualization, ambidextrous movements, a tremor filter, and more degrees of freedom of the effector tip movement than standard instruments. These theoretical benefits may be of specific significance in confined spaces. Recently, Intuitive Surgical (Sunnyvale, California) launched the da Vinci single port platform. The device combines a single site port with flexible robotic arms and instruments and improved ergonomics. Its use has mainly been described in gallbladder resections, gynecological operations, and urological procedures ${ }^{[36-39]}$. Jiménez-Rodríguez et al ${ }^{[38]}$ reported two cases of robotic low anterior resection with reduced ports, using the single-port robotic platform. There were no intraoperative complications and the pathology report showed complete TME specimens ${ }^{[38]}$. Atallah et al reported the first clinical case of robotic transanal TME in a patient with a T3N1 rectal tumor located $4 \mathrm{~cm}$ from the anal verge. There were no complications, negative distal and circumferential margins were achieved, and the specimen quality was near-complete ${ }^{[40]}$. Verheijen et al. ${ }^{[41]}$ reported their first case of robotic TaTME without complications and histology showed a complete mesorectal excision with free distal and circumferential margins. Marks et $a l^{[42]}$. reported the successful transanal use of the single-port system robotic platform (SPS) on four cadavers. There were no piecemeal or fragmented resections and, subjectively, closure was deemed good-to-excellent in all cases. Surgeon assessment of setup and performance of the SPS was excellent in all cases ${ }^{[42,43]}$. Kuo et al ${ }^{[44]}$ reported the largest series to date of 15 consecutive patients with ultra-low rectal tumors who underwent robotic TaTME followed by trans-abdominal robotic single port proctectomy and one additional port. The median number of lymph nodes harvested was 12. All patients had negative circumferential and distal resection margins ${ }^{[4]}$.

Huscher et al ${ }^{[43]}$ reported seven cases of TME using a hybrid technique combining robotic TaTME and laparoscopic abdominal procedure (vessel division and colon mobilization). Macroscopic assessment showed complete mesorectum in six cases and near complete mesorectum in one case, the mean number of lymph nodes was 14 and DRM and CRM were negative in all cases ${ }^{[43]}$.

\section{CONCLUSION}

TaTME offers several potential advantages compared to standard transabdominal TME. Several trials are currently underway to test this hypothesis. The single port robot may further facilitate introduction and adaptation of the TaTME method of TME.

\section{DECLARATIONS}

\section{Author's contribution}

Writing manuscript, critical review and final edits: Wexner SD

Writing manuscript and final edits: Yellinek S 


\section{Availability of data and materials}

Not applicable.

\section{Financial support and sponsorship}

None.

\section{Conflicts of interest}

Dr. Wexner is a paid consultant and receives royalties from Intuitive Surgical Karl Storz Endoscopy, and Medtronic and consulting fees from Novodaq.

\section{Ethical approval and consent to participate}

Not applicable.

\section{Consent for publication}

Not applicable.

\section{Copyright}

(C) The Author(s) 2018.

\section{REFERENCES}

1. Heald RJ, Husband EM, Ryall RD. The mesorectum in rectal cancer surgery--the clue to pelvic recurrence? Br J Surg 1982;69:613-6.

2. Marks G, Mohiuddin M, Rakinic J. New hope and promise for sphincter preservation in the management of cancer of the rectum. Semin Oncol 1991;18:388-98.

3. Buess G, Theiss R, Günther M, Hutterer F, Pichlmaier H. Endoscopic surgery in the rectum. Endoscopy 1985;17:31-5.

4. Sylla P, Rattner DW, Delgado S, Lacy AM. NOTES transanal rectal cancer resection using transanal endoscopic mi crosurgery and laparoscopic assistance. Surg Endosc 2010;24:1205-10.

5. Maya A, Vorenberg A, Oviedo M, da Silva G, Wexner SD, Sands D. Surg Endosc. 2014 Learning curve for transanal endoscopic microsurgery: a single-center experience. Surg Endosc 2014;28:1407-12.

6. Atallah SB, Albert MR. Transanal minimally invasive surgery (TAMIS) versus transanal endoscopic microsurgery (TEM): is one better than the other? Surg Endosc 2013;27:4750-1.

7. Atallah SB, Larach S, deBeche-Adams TC, Albert MR. Transanal minimally invasive surgery (TAMIS): a technique that can be used for retrograde proctectomy. Dis Colon Rectum 2013;56:931.

8. Atallah S, Albert M, Debeche-Adams T, Nassif G, Polavarapu H, Larach S. Transanal minimally invasive surgery for total mesorectal excision (TAMIS-TME): a stepwise description of the surgical technique with video demonstration. Tech Coloproctol 2013;17:321-5.

9. Atallah S, Martin-Perez B, Albert M, deBeche-Adams T, Nassif G, Hunter L, Larach S. Transanal minimally invasive surgery for total mesorectal excision (TAMIS-TME): results and experience with the first 20 patients undergoing curative-intent rectal cancer surgery at a single institution. Tech Coloproctol 2014;18:473-80.

10. Lacy AM, Tasende MM, Delgado S, Fernandez-Hevia M, Jimenez M, De Lacy B, Castells A, Bravo R, Wexner SD, Heald RJ. Transanal Total Mesorectal Excision for Rectal Cancer: Outcomes after 140 Patients. J Am Coll Surg 2015;221:415-23.

11. de Lacy FB, van Laarhoven JJEM, Pena R, Arroyave MC, Bravo R, Cuatrecasas M, Lacy AM. Transanal total mesorectal excision: pathological results of 186 patients with mid and low rectal cancer. Surg Endosc 2018;32:2442-7.

12. Penna M, Hompes R, Arnold S, Wynn G, Austin R, Warusavitarne J, Moran B, Hanna GB, Mortensen NJ, Tekkis PP; TaTME Registry Collaborative. Transanal Total Mesorectal Excision: International Registry Results of the First 720 Cases. Ann Surg 2017;266:111-7.

13. Penna M, Hompes R, Arnold S, Wynn G, Austin R, Warusavitarne J, Moran B, Hanna GB, Mortensen NJ, Tekkis PP; International TaTME Registry Collaborative. Incidence and risk factors for anastomotic failure in 1594 patients treated by transanal total mesorectal excision: results from the International TaTME Registry. Ann Surg 2018 Jan 5. doi: 10.1097/SLA.0000000000002653.

14. Koedam TW, van Ramshorst GH, Deijen CL, Elfrink AK, Meijerink WJ, Bonjer HJ, Sietses C, Tuynman JB. Transanal total mesorectal excision (TaTME) for rectal cancer: effects on patient-reported quality of life and functional outcome. Tech Coloproctol 2017;21:25-33.

15. Marks JH, Myers EA, Zeger EL, Denittis AS, Gummadi M, Marks GJ. Long-term outcomes by a transanal approach to total mesorectal excision for rectal cancer. Surg Endosc 2017;31:5248-57.

16. Perdawood SK, Thinggaard BS, Bjoern MX. Effect of transanal total mesorectal excision for rectal cancer: comparison of short-term outcomes with laparoscopic and open surgeries. Surg Endosc 2018; 32:2312-21.

17. Deijen CL, Velthuis S, Tsai A, Mavroveli S, de Lange-de Klerk ES, Sietses C, Tuynman JB, Lacy AM, Hanna GB, Bonjer HJ. COLOR III: a multicentre randomised clinical trial comparing transanal TME versus laparoscopic TME for mid and low rectal cancer. Surg Endosc 2016;30:3210-5.

18. Lelong B, de Chaisemartin C, Meillat H, Cournier S, Boher JM, Genre D, Karoui M, Tuech JJ, Delpero JR; French Research Group of RectalCancer Surgery (GRECCAR). A multicentre randomised controlled trial to evaluate the efficacy, morbidity and functional outcome of endoscopic transanal proctectomy versus laparoscopic proctectomy for low-lying rectal cancer (ETAP-GRECCAR 11 TRIAL): 
rationale and design. BMC Cancer 2017;171:253.

19. Abbott SC, Stevenson ARL, Bell SW, Clark D, Merrie A, Hayes J, Ganesh S, Heriot AG, Warrier SK. An assessment of an Australasian pathway for the introduction of transanal total mesorectal excision (taTME). Colorectal Dis 2018;20:O1-6.

20. Adamina M, Buchs NC, Penna M, Hompes R; St. Gallen Colorectal Consensus Expert Group. St. Gallen consensus on safe implementation of transanal total mesorectal excision. Surg Endosc 2018;32:1091-103.

21. Atallah SB, DuBose AC, Burke JP, Nassif G, deBeche-Adams T, Frering T, Albert MR, Monson JRT. Uptake of Transanal Total Mesorectal Excision in North America: Initial Assessment of a Structured Training Program and the Experience of Delegate Surgeons. Dis Colon Rectum 2017;60:1023-31.

22. Francis N, Penna M, Mackenzie H, Carter F, Hompes R; International TaTME Educational Collaborative Group. Consensus on structured training curriculum for transanal total mesorectal excision (TaTME). Surg Endosc 2017;31:2711-9.

23. Koedam TWA, Veltcamp Helbach M, van de Ven PM, Kruyt PM, van Heek NT, Bonjer HJ, Tuynman JB, Sietses C. Transanal total mesorectal excision for rectal cancer: evaluation of the learning curve. Tech Coloproctol 2018;22:279-87.

24. McLemore EC, Harnsberger CR, Broderick RC, Leland H, Sylla P, Coker AM, Fuchs HF, Jacobsen GR, Sandler B, Attaluri V, Tsay AT, Wexner SD, Talamini MA, Horgan S. Transanal total mesorectal excision (taTME) for rectal cancer: a training pathway. Surg Endosc 2016;30:4130-5.

25. Penna M, Whiteford M, Hompes R, Sylla P. Developing and assessing a cadaveric training model for transanal total mesorectal excision: initial experience in the UK and USA. Colorectal Dis 2017;19:476-84.

26. Koedam TWA, Veltcamp Helbach M, van de Ven PM, Kruyt PM, van Heek NT, Bonjer HJ, Tuynman JB, Sietses C. Transanal total mesorectal excision for rectal cancer: evaluation of the learning curve. Tech Coloproctol 2018;224:279-87.

27. Araujo SE, Crawshaw B, Mendes CR, Delaney CP. Transanal total mesorectal excision: a systematic review of the experimental and clinical evidence. Tech Coloproctol 2015;19:69-82.

28. Atallah S, Albert M, Monson JR. Critical concepts and important anatomic landmarks encountered during transanal total mesorectal excision (taTME): toward the mastery of a new operation for rectal cancer surgery. Tech Coloproctol 2016;20:483-94.

29. Penna M, Cunningham C, Hompes R. Transanal Total Mesorectal Excision: Why, When, and How. Clin Colon Rectal Surg 2017;30:339-45.

30. de Lacy FB, van Laarhoven JJEM, Pena R, Arroyave MC, Bravo R, Cuatrecasas M, Lacy AM. Transanal total mesorectal excision: pathological results of 186 patients with mid and low rectal cancer. Surg Endosc 2018;32:2442-7

31. Jiang PH, Li YS, Wang B, Wang C, Liu F, Shen ZL, Ye YJ, Wang S. Pathological outcomes of transanal versus laparoscopic total mesorectal excision for rectal cancer: a systematic review with metaanalysis. Surgical Endoscopy 2018;32:2632-42.

32. Leo CA, Samaranayake S, Perry-Woodford ZL, Vitone L, Faiz O, Hodgkinson JD, Shaikh I, Warusavitarne J. Initial experience of restorative proctocolectomy for ulcerative colitis by transanal total mesorectal rectal excision and single-incision abdominal laparoscopic surgery. Colorectal Dis 2016;18:1162-6.

33. Carvello M, David G, Sacchi M, Di Candido F, Spinelli A. Restorative proctocolectomy and IPAA for right sided colonic adenocarcinoma on FAP: abdominal laparoscopic approach combined with transanal total mesorectal excision - video vignette. Colorectal Dis 2018;20:355-6.

34. Ambe PC, Zirngibl H, Möslein G. Initial experience with taTME in patients undergoing laparoscopic restorative proctocolectomy for familial adenomatous polyposis. Tech Coloproctol 2017;21:971-4.

35. Trépanier JS, Arroyave MC, Bravo R, Jiménez-Toscano M, DeLacy FB, Fernandez-Hevia M, Lacy AM. Transanal Hartmann's colostomy reversal assisted by laparoscopy: outcomes of the first 10 patients. Surg Endosc 2017;31:4981-7.

36. Arezzo A, Mintz Y, Allaix ME, Arolfo S, Bonino M, Gerboni G, Brancadoro M, Cianchetti M, Menciassi A, Wurdemann H, Noh Y, Althoefer K, Fras J, Glowka J, Nawrat Z, Cassidy G, Walker R, Morino M. Total mesorectal excision using a soft and flexible robotic arm: a feasibility study in cadaver models. Surg Endosc 2017;31:264-273.

37. Bae SU, Jeong WK, Bae OS, Baek SK. Reduced-port robotic anterior resection for left-sided colon cancer using the Da Vinci singlesite(®) platform. Int J Med Robot 2016;12:517-23.

38. Jiménez-Rodríguez RM, Pavón JM, de la Portilla F, Sillero EP, Dussort JM, Padillo J. Robotic-assisted total mesorectal excision with the aid of a single-port device. Surg Innov 2013;20:NP3-5.

39. Lee GC, Sylla P. Shifting Paradigms in Minimally Invasive Surgery: Applications of Transanal Natural Orifice Transluminal Endoscopic Surgery in Colorectal Surgery. Clin Colon Rectal Surg 2015;28:181-93.

40. Atallah S, Drake J, Martin-Perez B, Kang C, Larach S. Robotic transanal total mesorectal excision with intersphincteric dissection for extreme distal rectal cancer: a video demonstration. Tech Coloproctol 2015;19:435.

41. Verheijen PM, Consten EC, Broeders IA. Robotic transanal total mesorectal excision for rectal cancer: experience with a first case. Int J Med Robot 2014;10:423-6.

42. Marks J, Ng S, Mak T. Robotic transanal surgery (RTAS) with utilization of a next-generation single-port system: a cadaveric feasibility study. Tech Coloproctol 2017;21:541-5.

43. Huscher CG, Bretagnol F, Ponzano C. Robotic-assisted transanal total mesorectal excision: the key against the Achilles' heel of rectal cancer? Ann Surg 2015;261:e120-1.

44. Kuo LJ, Ngu JC, Tong YS, Chen CC. Combined robotic transanal total mesorectal excision (R-taTME) and single-site plus one-port (RSSPO) technique for ultra-low rectal surgery-initial experience with a new operation approach. Int J Colorectal Dis 2017;32:249-54. 